\title{
THE DEVELOPMENT AND CALIBRATION OF THE BENCHMARK SLEEVE FOR LEVELLING ELEVATION POINTS WHICH ARE PARTIALLY RECESSED
}

\author{
Janusz KUCHMISTER*, Piotr GOLUCH, \\ Kazimierz ĆMIELEWSKI and Krzysztof MĄKOLSKI
}

Institute of Geodesy and Geoinformatics, Wroclaw University of Environmental and Life Sciences, Grunwaldzka 53, 50-357 Wroclaw, Poland

*Corresponding author's e-mail: janusz.kuchmister@up.wroc.pl

\section{ARTICLE INFO}

Article history:

Received 1 December 2014

Accepted 3 March 2015

Available online 22 April 2015

\section{Keywords}

Geometric levelling

Engineering measurements of elevation

Benchmark snap-in

\section{ABSTRACT}

As a result of different works on the buildings wall (insulation, installing billboards or mailboxes, etc.) the access to the existing benchmarks may be hindered and as a result it may be difficult to perform geometric levelling using classical measuring equipment. For this reason, the authors have developed and created a prototype of a mechanical benchmark snap-in. Its construction and principle of operation are presented in this paper. As part of the research and experimental works carried out under the laboratory conditions the instrument was calibrated and its functionality and accuracy were designated. On the basis of height differences between benchmarks which were determined using the benchmark snap-in, it was found that the average accuracy of the height difference designation under the laboratory conditions, where the length of the line of sight is $4 \mathrm{~m}$, does not exceed $\pm 0.01 \mathrm{~mm}$.

\section{INTRODUCTION}

Measurements of height differences are the basis for various levelling works in the national economy and monitoring of rock blocks displacements (Hanzl, 2011; Pelzer, 1988). It is due to the fact that it is necessary to maintain in the space the correct position of technical infrastructure elements and buildings and to do levelling measurements which are crucial for presenting the relief on maps.
Insulation added to the external walls impedes the access or makes it impossible to access geodetic height signs (benchmarks) that were affixed to the walls. Figure 1 shows different types of recessed height points that belong to the national and local control networks and which are used to determine vertical displacements of buildings.

The specialised literature includes a description of various devices relying on the established geodetic a).

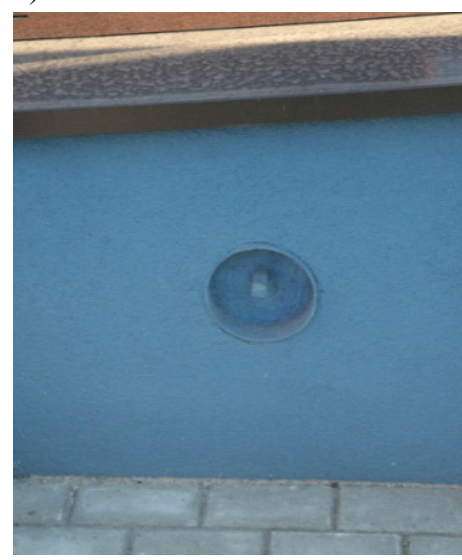

b).

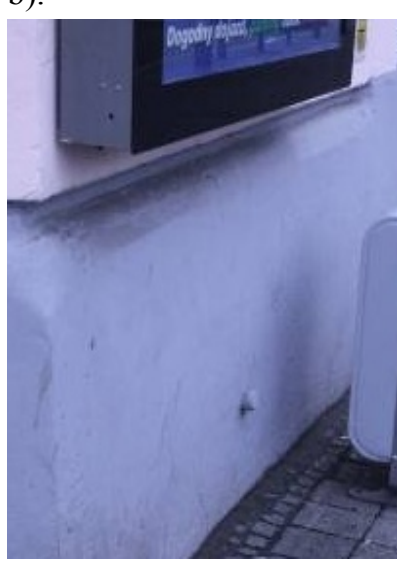

c).

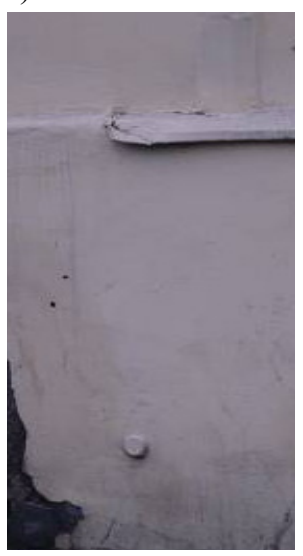

d).

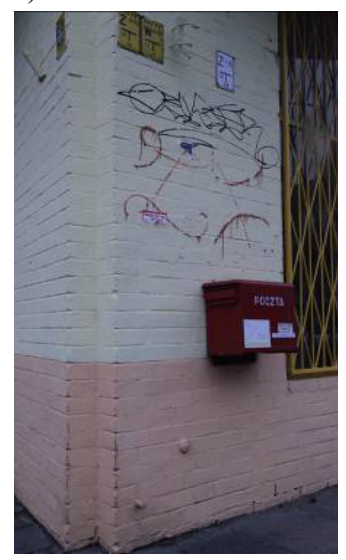

Fig. 1 The view of partly recessed elevation points. Benchmarks cannot be accessed due to:

a) adding insulation and installing the window sill;

b) installing the billboard on the building wall;

c) installing the window sill on the façade of the building;

d) installing the mailbox and the flagpole bracket on the wall of the building. 
a).

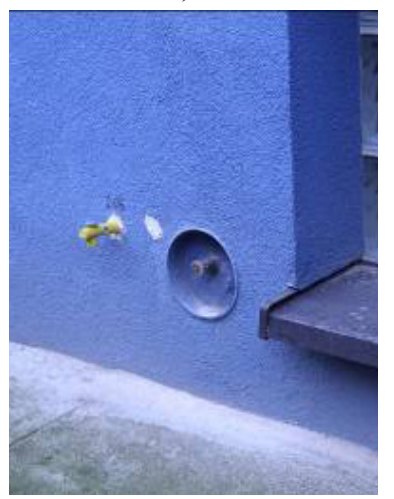

b).

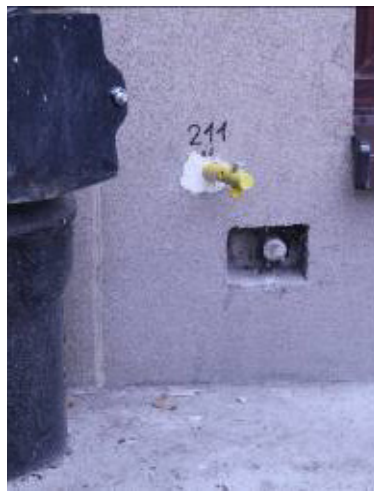

c).

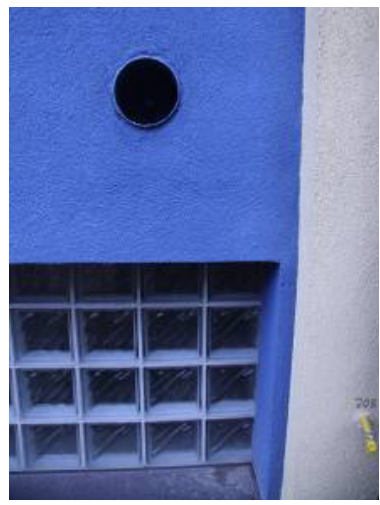

d).

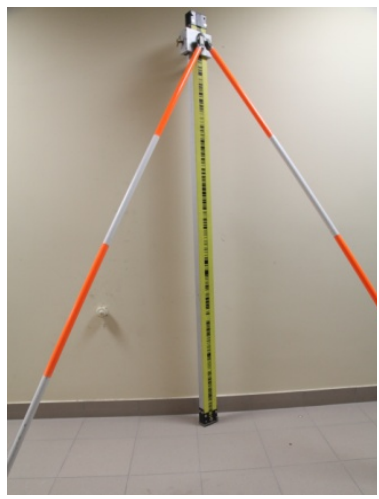

Fig. 2 The view of partially recessed benchmarks and working benchmarks to which heights were transferred using a sleeve snap-in:

a), b) and c) the view of stabilised working benchmarks;

d) the view of the intermediate height measuring point.

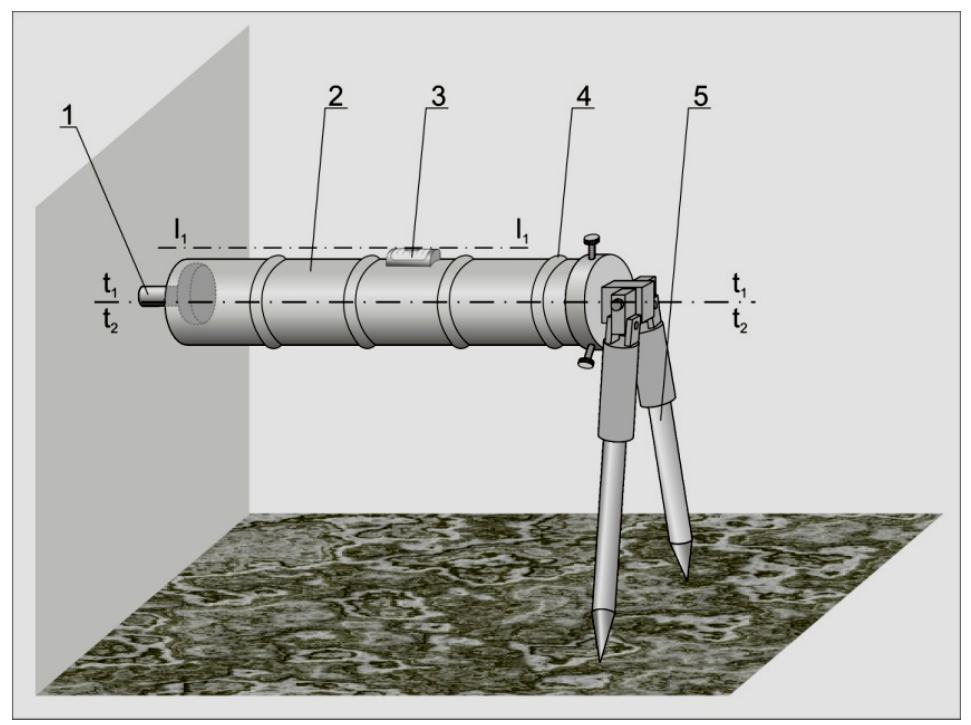

Fig. 3 The view of the mechanical tubular snap-in

Parts: 1. wall benchmark; 2. sleeve snap-in; 3. tubular level; 4. benchmark ring; 5 . bracket; $1_{1}-1_{1}$ - tubular level axis; $t_{1}-t_{1}$ - axis of the inner surface of the sleeve; $t_{2}-t_{2}-$ axis of the outer surface of the sleeve.

methods which can be used to do levelling or improve levelling using partially inaccessible (recessed) benchmarks (Ćmielewski, 2007; Ćmielewski et al., 2013; Schofield and Breach, 2007). These are the solutions based on the principles of trigonometric levelling (Kavanagh, 2010; Mora, 1998), hydrostatic levelling (Gocał, 1993; Hennecke and Werner, 1982) or the ones that utilize photogrammetric measurements (Kuchmister et al., 2014).

In order to use partly recessed benchmarks (Fig. 1) in levelling, the authors have developed and built an innovative mechanical device (sleeve snap-in) which enables to transfer heights from such benchmarks to the other benchmark or an intermediate height measuring point (foot plate or wedge) by means of geometric levelling (Fig. 2). This instrument features simple construction and easy handling .

\section{DESIGN AND OPERATING PRINCIPLE OF THE SLEEVE SNAP-IN}

A mechanical sleeve snap-in (Fig 3.) is an elongated, appropriately turned sleeve with an embedded tubular level and a bracket that keeps the snap-in horizontal. The inner surface of the presented snap-in is placed on the partly recessed benchmark while the outer surface has a number of rings which serve as intermediate height points (temporary benchmarks with transferred heights). A prototype of the benchmark snap-in has four rings, to which numbers from I (place where the snap-in was installed on the benchmark) to IV (bracket vicinity) were assigned. During measurements the foot of the levelling staff is placed on the selected benchmark ring. 


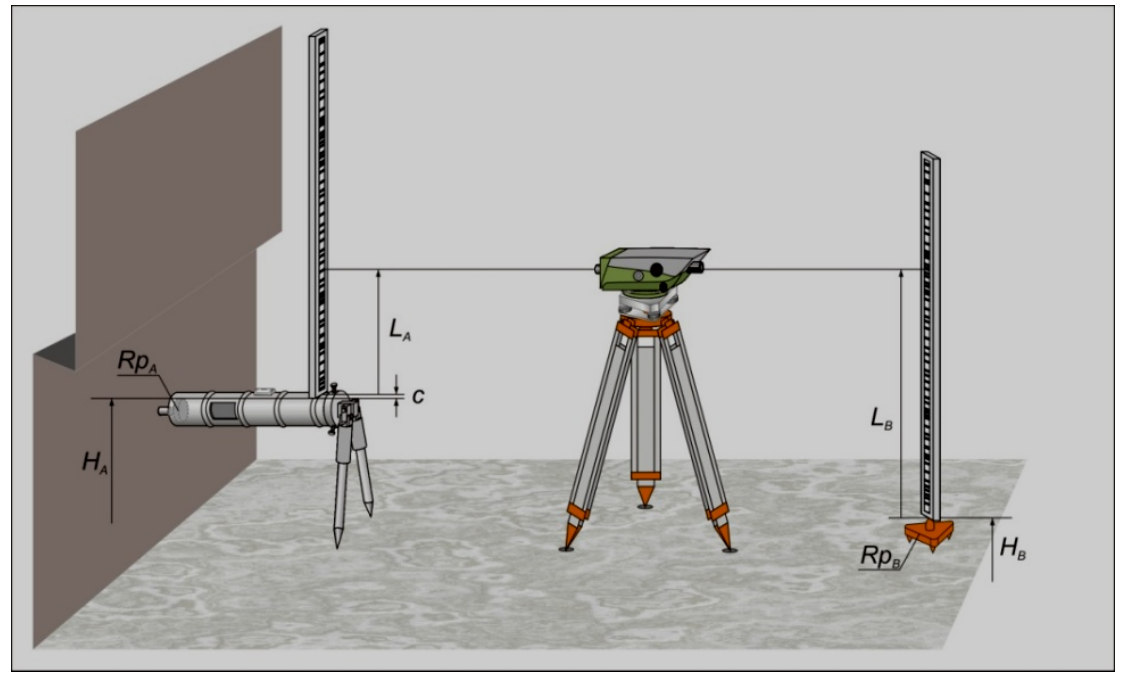

Fig. 4 The gist of transferring height from the partially recessed benchmark to the temporary height point (foot plate).

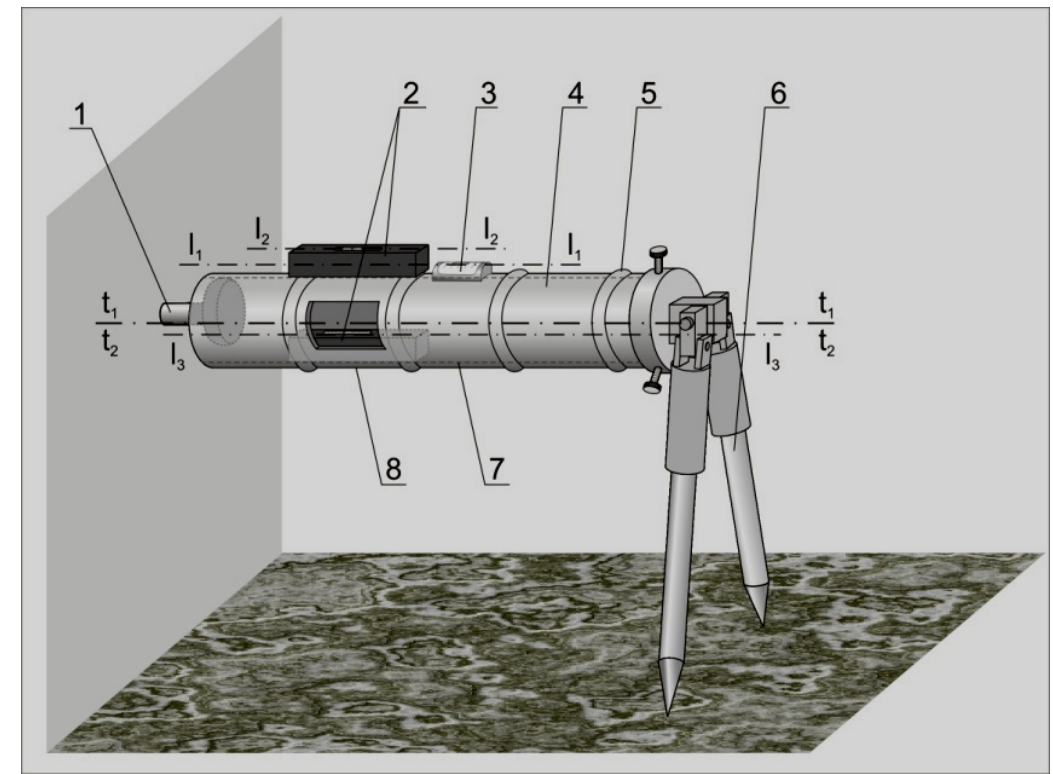

Fig. 5 Calibration of the mechanical sleeve snap-in

Parts: 1. wall benchmark; 2. precise machine level; 3. tubular level; 4. sleeve snap-in; 5. benchmark ring; 6 . bracket; 7. the inner surface of the sleeve; 8 . the outer surface of the sleeve; $1_{1}-1_{1}$ - axis of the tubular level; $1_{2}-1_{2}$ - axis of the machine level set on the benchmark rings; $1_{3}-l_{3}$ - axis of the machine level placed inside the sleeve; $t_{1}-t_{1}$ - axis of the inner surface of the sleeve; $t_{2}-t_{2}$ - axis of the outer surface of the sleeve.

A snap-in is made of homogeneous material whose external and internal surfaces are slightly rough and are turned with the precision that ensures adequate (set) tolerance of results. In the designed sleeve the circularity of the inner surface, the circularity of the outer benchmark rings, as well as concentricity of the inner (axis $t_{1}-t_{1}$ ) and external (axis $t_{2}-t_{2}$ ) surface of the sleeve should be maintained. In the properly built and calibrated snap-in the condition that the sleeve axes $t_{1}-t_{1}$ and $t_{2}-t_{2}$ are parallel to the axis of the tubular level ${ }_{1}-l_{1}$ should be met. Due to occurrence of errors while turning the surface of the sleeve and benchmark rings, the snap-in should be calibrated before measurements. During calibration the constant $c$ value for every single ring (Fig. 4) should be determined. This value is the distance between the inner surface of the sleeve and the outer surface of the set benchmark ring. Values of the constant $c_{i}$ determined for each of the rings must be taken into account when measuring with the benchmark snap-in. 


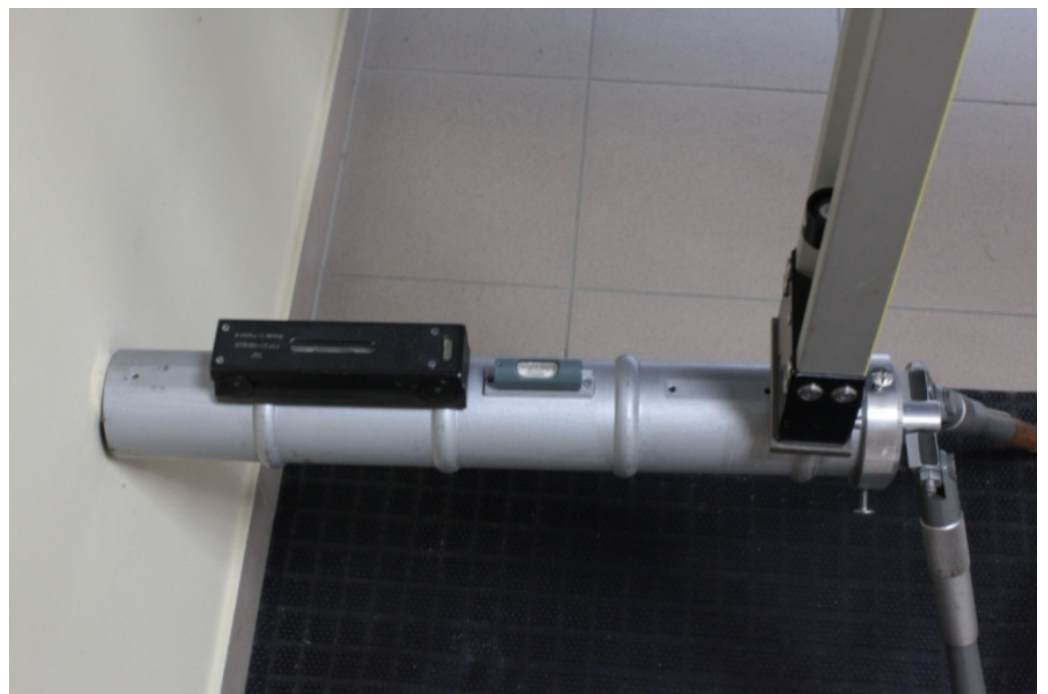

Fig. 6 The view of the mechanical sleeve snap-in during calibration.

In order to transfer heights from the wall benchmark to the temporary height point (footplate) Figure 4, the calibrated snap-in should be placed on the benchmark so that the inner surface of the sleeve lies on the benchmark head. Then with the help of the bracket legs, the tubular level should be levelled. After correct installation of the snap-in on the benchmark, the foot of the levelling staff is placed on the set benchmark ring and geometric levelling is done (Fig. 4). The elevation of the temporary height point (foot plate) is determined on the basis of the equation (1).

$$
H_{B}=H_{A}+L_{A}+c-L_{B}
$$

\section{CALIBRATION OF THE BENCHMARK SLEEVE PROTOTYPE}

Due to possible inaccuracies while processing the surfaces of the benchmark sleeve, the sleeve should be calibrated prior to levelling.

The aim of calibration is to check geometric conditions which should be met by the inner surface axis $\left(t_{1}-t_{1}\right)$ and the outer surface axis $\left(t_{2}-t_{2}\right)$ of the benchmark sleeve and the axis $\left(l_{1}-l_{1}\right)$ of the tubular level (Fig. 5). Calibration may be done using one or two precise machine, tubular levels, whose location on the respective surfaces of the sleeve snap-in is illustrated in Figure 5.

After levelling the machine level using the bracket legs, the tubular level is rectified. While rectifying the snap-in, the levelling staff placed on every benchmark ring was read a few times. Measurements were taken with a precise digital level Leica DNA03 (Fig. 6). The results of the measurements were registered in the measurement documentation.

On the basis of the calibration, it was found that the differences of diameters of the benchmark rings vary within $\pm 0.18 \mathrm{~mm}$ and that their axes are mutually shifted within $\pm 0.1 \mathrm{~mm}$. Due to this fact, the correction values for benchmark rings were determined and they are presented in Table 1.

Table 1 Constants $c_{i}$ determined for the benchmark rings.

\begin{tabular}{lccccc}
\hline $\begin{array}{l}\text { The number of the } \\
\text { benchmark ring }\end{array}$ & I & II & III & IV \\
\hline $\begin{array}{l}\text { Values of the } \\
\text { constant }\end{array} \quad \begin{array}{c}c_{i} \\
{[\mathrm{~mm}]}\end{array}$ & 9.430 & 9.430 & 9.540 & 9.770 \\
\hline
\end{tabular}

Values of the constant $c_{i}$ for the rings I and II are the same and come to $c_{I}=c_{I I}=9.430 \mathrm{~mm}$ (which results from the method of the snap-in calibration), and the constants for the benchmark rings III and IV are $c_{I I I}=9.540 \mathrm{~mm}$ and $c_{I V}=9.770 \mathrm{~mm}$ respectively.

\section{LABORATORY EXAMINATION OF THE LEVELLING ACCURACY USING A PROTOTYPE OF THE BENCHMARK SLEEVE}

After calibrating the device, experimental works were done whose aim was to determine functionality and accuracy of measurements. For this purpose a equence of observations under the laboratory conditions was made using benchmarks stabilised in the underground of the Institute of Geodesy and Geoinformatics at the University of Environmental and Life Sciences in Wrocław. A precise level Leica DNA03 and a bar-code levelling staff were used in measurements. At the beginning of measurements the height difference between two benchmarks was determined without using the benchmark snap-in (Fig. 7). Then, measurements were taken with the snap-in set on all benchmark rings (Fig. 8). Height differences were measured in a several measuring series with different line of sights of the levelling instrument. On the basis of levelling where no snap-in 


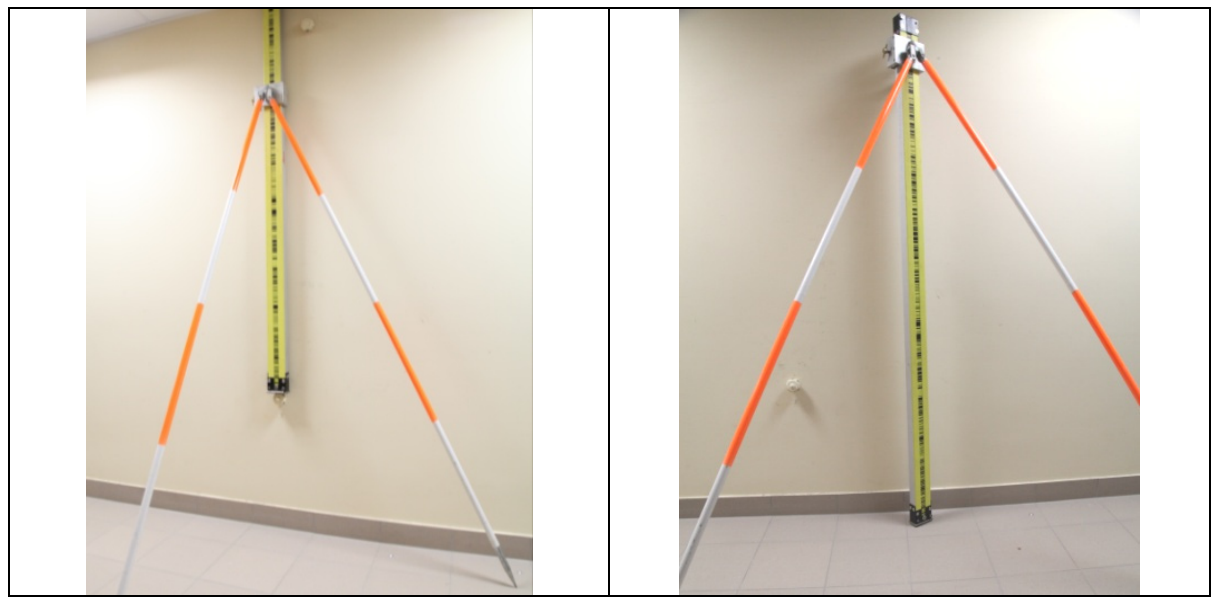

Fig. 7 Determination of height differences between benchmarks.

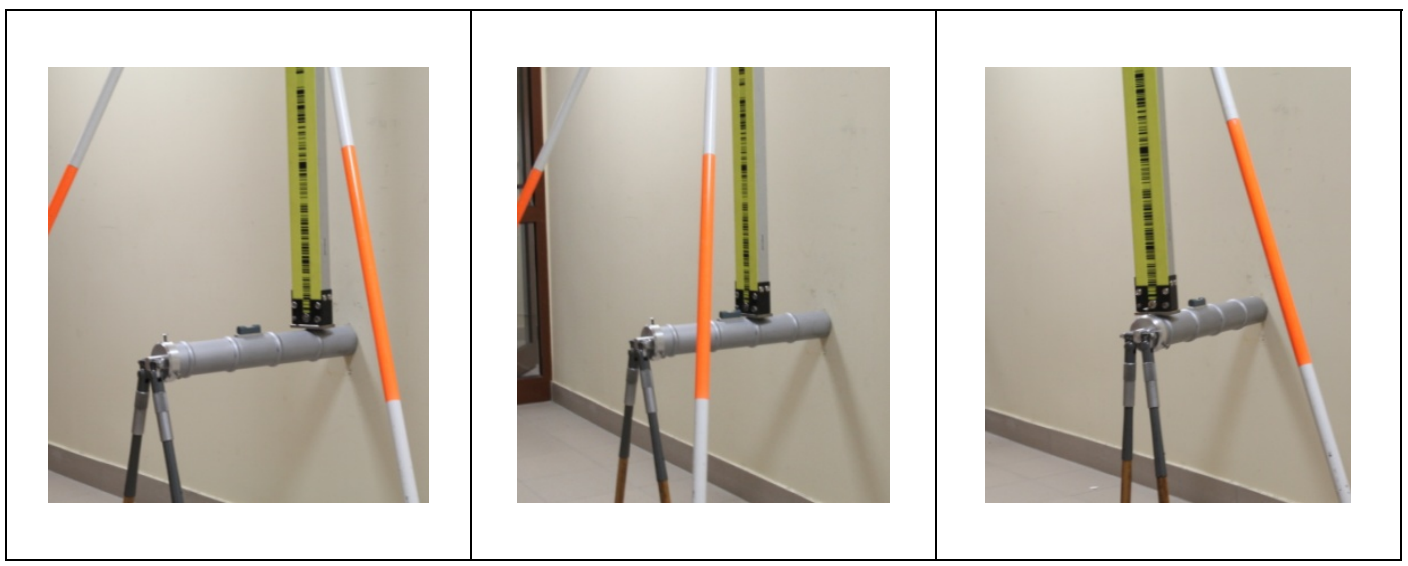

Fig. 8 Determination of height difference between benchmarks using the benchmark snap-in.

Table 2 Constants $c_{i}$ determined for each particular benchmark ring.

\begin{tabular}{lccccc}
\hline The number of the benchmark ring & & I & II & III & IV \\
\hline The value of the height difference & $\begin{array}{c}\Delta h \\
{[\mathrm{~m}]}\end{array}$ & -0.631360 & -0.631358 & -0.631360 & -0.631351 \\
& $\begin{array}{c}m_{\Delta h} \\
{[\mathrm{~mm}]}\end{array}$ & \pm 0.008 & \pm 0.004 & \pm 0.007 & \pm 0.007 \\
$\begin{array}{l}\text { The average error of the determined } \\
\text { height difference }\end{array}$ & & & & \\
\hline
\end{tabular}

was used, the so-called 'model' value of the height difference was calculated. This value amounted to $0.631358 \mathrm{~m}$, and the mean error was $\pm 0.004 \mathrm{~mm}$. Constants $c_{i}$ determined for each particular ring were considered in the compilation of results (Table 1). The average values of the calculated height differences between benchmarks and their mean errors are presented in Table 2.

\section{SUMMARY AND CONCLUSIONS}

The conducted experimental research works demonstrate the usefulness of designed and created mechanical benchmark snap-in in transferring heights from the partly recessed benchmarks to other benchmarks or temporary height points. After creating the benchmark snap-in, the device should be calibrated according to guidelines described in this paper. The values of constants $c_{i}$ determined in the calibration process for each particular ring should be considered using the equation (1) when calculating the height difference between the partially recessed benchmark and the benchmark (temporary height point) to which the height is transferred (Fig. 4). On the basis of determined differences between 
benchmarks and using the rings of the benchmark snap-in, accuracy of designating height differences under laboratory conditions (for line of sight which is approx. $4 \mathrm{~m}$ ) is between $\pm 0.004 \mathrm{~mm}$ and $\pm 0.008 \mathrm{~mm}$ and is similar to the accuracy of designating this height difference without the use of the snap-in. The accuracy of the height difference determined using Leica DNA03 level, the bar-code levelling staff and the benchmark snap-in described in this papers is in accordance with the Polish Regulation (Rozporządzenie, 2012) of 2012 for precise levelling. When levelling with the snap-in it is favourable to set the staff at least on two benchmark rings in order to increase the accuracy and reinforce controls on the results.

\section{REFERENCES}

Ćmielewski, K., Gołuch, P., Kuchmister, J., Mąkolski, K., Bryś, H. and Kowalski, K.: 2013, The transfer of height of benchmarks partially unavailable in industrial environments. XI scientific and technical conference dedicated to the memory of Professor Dr. Tadeusz Lazzarini the 100th anniversary of his birth, "Current Problems in Surveying Engineering", Poland, Warszawa-Serock, 14-16.03.2013 (poster, conference materials), (in Polish).

Ćmielewski, K.: 2007, Fibre optics and laser technology in high precision measurements of shapes and deformations of engineering objects. ZN UP we Wrocławiu, Nr 551, Rozprawy CCXLVI, Wrocław, 242 pp., (in Polish).

Gocal, J.: 1993, Surveying methods and instruments for precision measurement of machines and mechanical appliances, Wydawnictwo AGH, Kraków, 244 pp., (in Polish).

Hanzl, V.: 2011, Monitoring of rock blocks movements. Acta Montanistica Slovaca, 16, 4, 287-290.

Hennecke, F. and Werner, H.: 1982, Ingenieur-GeodäsieAnwendung im Bauwesen und Maschinenbau, VEB Verlag für Bauwesen, Berlin, (in German), 559 pp.
Kavanagh, B.F.: 2010, Surveying with construction applications. 7th ed., Prentice Hall, New Jersey, $704 \mathrm{pp}$.

Kuchmister, J., Ćmielewski, K. and Gołuch, P.: 2014, The application of the optoelectronic technique of transferring heights from the recessed benchmarks in networks in the examination of rock mass deformation. Acta Geodyn. Geomater., 11, No. 1(173), 23-33. DOI: 10.13168/AGG. 2013.0052

Mora, A.S.:1998, Industrial applications of surveying. Colegio Oficial de Ingenieros Técnicos en Topografía, Madrid-Castilla-La Mancha, 367 pp., (in Spain).

Pelzer, H.: 1988, Ingenieurvermessung - Deformationsmessungen - Massenberechnung (Engineering Surveying - Deformation measurements - Bulk calculation). Ergebnisse des Arbeitskreises 6 des Deutschen Vereins für Vermessungswesen (DVW) e.V., Verlag Konrad Witwer, Stuttgart, (in German).

Rozporządzenie Ministra Administracji i Cyfryzacji z dnia 14 lutego 2012r. w sprawie osnów geodezyjnych, grawimetrycznych i magnetycznych (Regulation of the Minister of Administration and Digitization of 14 February 2012 on the geodetic, gravimetric and magnetic networks), Dz. U. z 30 marca 2012 poz. 352 (http://isap.sejm.gov.pl/DetailsServlet?id=WDU20120 000352), (in Polish).

Schofield, W. and Breach, M.: 2007, Engineering surveying. 6th ed. Elsevier Ltd., Oxford, UK, 622 pp. 